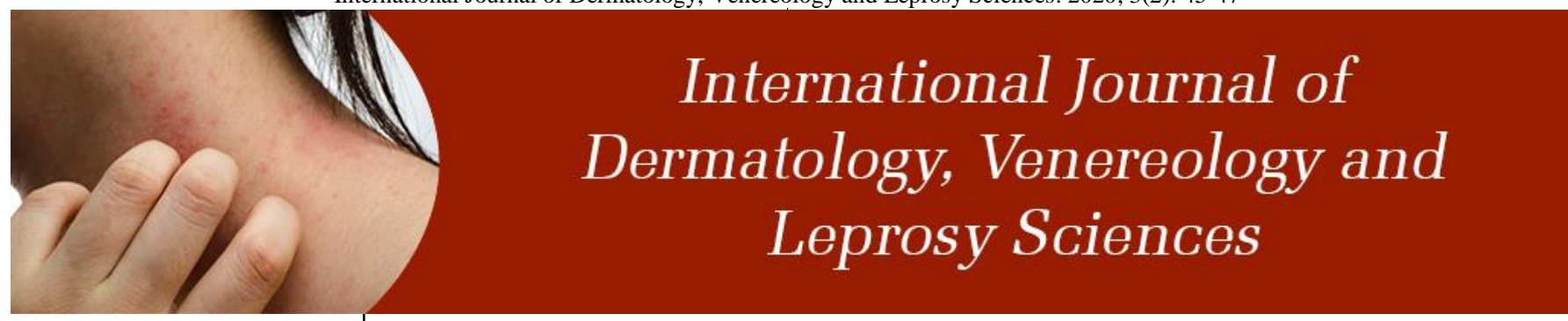

E-ISSN: 2664-942X P-ISSN: 2664-9411 www.dermatologypaper.com Derma 2020; 3(2): 45-47 Received: 14-05-2020 Accepted: 19-07-2020

Dr. Mohan Lal Gupta Associate Professor Dept of Dermatology, Venereology and Leprosy FH Medical College and Hospital, Tundla, Firozabad, U.P., India
Corresponding Author: Dr. Mohan Lal Gupta Associate Professor Dept of Dermatology, Venereology and Leprosy FH Medical College and Hospital, Tundla, Firozabad, U.P., India

\section{Assessment of cases of Atopic dermatitis- A clinical study}

\section{Dr. Mohan Lal Gupta}

DOI: https://doi.org/10.33545/26649411.2020.v3.i2a.45

\begin{abstract}
Background: Atopic dermatitis (AD) is a chronic inflammatory skin disease. The present study was conducted to assess cases of Atopic dermatitis.

Materials \& Methods: The present study was conducted among 140 children age ranged 8-12 years of AD. History of weight status, type of delivery, antibiotic use in the first year of life, breastfeeding, asthma history, and rhinitis history was recorded.

Results: Out of 140 patients, males were 80 and females were 60.105 children had history of asthma, 35 had not, 110 had history of allergic rhinitis and 30 had not. We found 75 were overweight and 65 were underweight, 90 were born by ceasaran section and 50 by normal vaginal delivery, 95 had antibiotic use in first year of life and 45 had not, 102 had breastfeeding $>4$ months and 38 had not. The difference was significant $(P<0.05)$.

Conclusion: Atopic dermatitis is highly prevalent in children. It has considerable social and economic burdens on patients, families and societies.
\end{abstract}

Keywords: atopic dermatitis, allergic rhinitis, children

\section{Introduction}

Atopic dermatitis (AD) is a chronic inflammatory skin disease of complex etiology. Although $\mathrm{AD}$ is primarily recognized as a disease of children, increasing evidence suggests that it is more common in adults than previously thought ${ }^{[1]}$. Prior studies focused primarily on the prevalence of $\mathrm{AD}$ in the pediatric population, yet only a handful examined the prevalence in the adult population ${ }^{[2]}$.

Dermatitis derives from the Greek "derma" which means skin, and "itis," which means inflammation. Dermatitis and eczema are often used synonymously, although the term eczema is sometimes reserved for the acute manifestation of the disease (from Greek, ekzema, to boil over); here, no distinction is made ${ }^{[3]}$. Over the years, many other names have been proposed for the disease, for instance, prurigo Besnier (Besnier's itch), named after the French dermatologist Ernest Besnier. Allergic sensitization and elevated immunoglobulin E (IgE) are present in only about half of all patients with the disease, and therefore atopic dermatitis is not a definitive term ${ }^{[4]}$.

Around 50\% of all those with atopic dermatitis develop symptoms within their first year of life, and probably as many as $95 \%$ experience an onset below five years of age ${ }^{[5]}$. Around $75 \%$ with childhood onset of the disease have a spontaneous remission before adolescence, whereas the remaining $25 \%$ continue to have eczema into adulthood or experience a relapse of symptoms after some symptom-free years. Many with adult-onset atopic dermatitis or atopic dermatitis relapsing in adulthood develop hand eczema as the main manifestation. To formulate a societal solution to these problems, an epidemiological study of the prevalence and risk factors of $\mathrm{AD}$ is needed ${ }^{[6]}$. The present study was conducted to assess cases of Atopic dermatitis.

\section{Materials \& Methods}

The present study was conducted in the department of dermatology. It comprised of 140 children age ranged 8-12 years of $\mathrm{AD}$ of both genders. Parents were informed and their consent was obtained. Ethical clearance was also obtained.

Data such as name, age, gender etc. was recorded. A thorough examination was done. 
Parameters such as weight status, type of delivery, antibiotic use in the first year of life, bronchiolitis before two years old, birth weight, older siblings, younger siblings, breastfeeding, time of introducing solid food, asthma history, and rhinitis history was recorded. A questionnaires modified from the International Study of Asthma and Allergy in Childhood (ISAAC) questionnaire was used. Results thus obtained were evaluated. P value less than 0.05 was considered significant.

\section{Results}

Table I: Distribution of patients

\begin{tabular}{|c|c|c|}
\hline \multicolumn{3}{|c|}{ Total- 140 } \\
\hline Gender & Boys & Girls \\
\hline Number & 80 & 60 \\
\hline
\end{tabular}

Table I shows that out of 140 patients, males were 80 and females were 60 .
Table II: Assessment of parameters

\begin{tabular}{|c|c|c|c|}
\hline Parameters & Factors & Number & P value \\
\hline \multirow{2}{*}{ Weight } & Overweight & 75 & \multirow{2}{*}{0.98} \\
\hline & Underweight & 65 & \\
\hline \multirow{2}{*}{ Type of delivery } & Cesarean & 90 & \multirow{2}{*}{0.07} \\
\hline & Vaginal & 50 & \\
\hline \multicolumn{2}{|c|}{ Antibiotic use in first year Yes } & 95 & \multirow{2}{*}{0.05} \\
\hline \multicolumn{2}{|c|}{ No } & 45 & \\
\hline \multicolumn{2}{|c|}{ Breastfeeding $>4$ months } & 102 & \multirow{2}{*}{0.016} \\
\hline \multicolumn{2}{|c|}{$<4$ months } & 38 & \\
\hline \multicolumn{2}{|c|}{ History of asthma Yes } & 105 & \multirow{2}{*}{0.012} \\
\hline \multicolumn{2}{|c|}{ No } & 35 & \\
\hline \multicolumn{2}{|c|}{ History of allergic rhinitis Yes } & 110 & \multirow{2}{*}{0.01} \\
\hline \multicolumn{2}{|c|}{ No } & 30 & \\
\hline
\end{tabular}

Table II, graph I shows that 75 were overweight and 65 were underweight, 90 were born by ceasaran section and 50 by normal vaginal delivery, 95 had antibiotic use in first year of life and 45 had not, 102 had breastfeeding >4 months and 38 had not, 105 had history of asthma, 35 had not, 110 had history of allergic rhinitis and 30 had not. The difference was significant $(P<0.05)$.

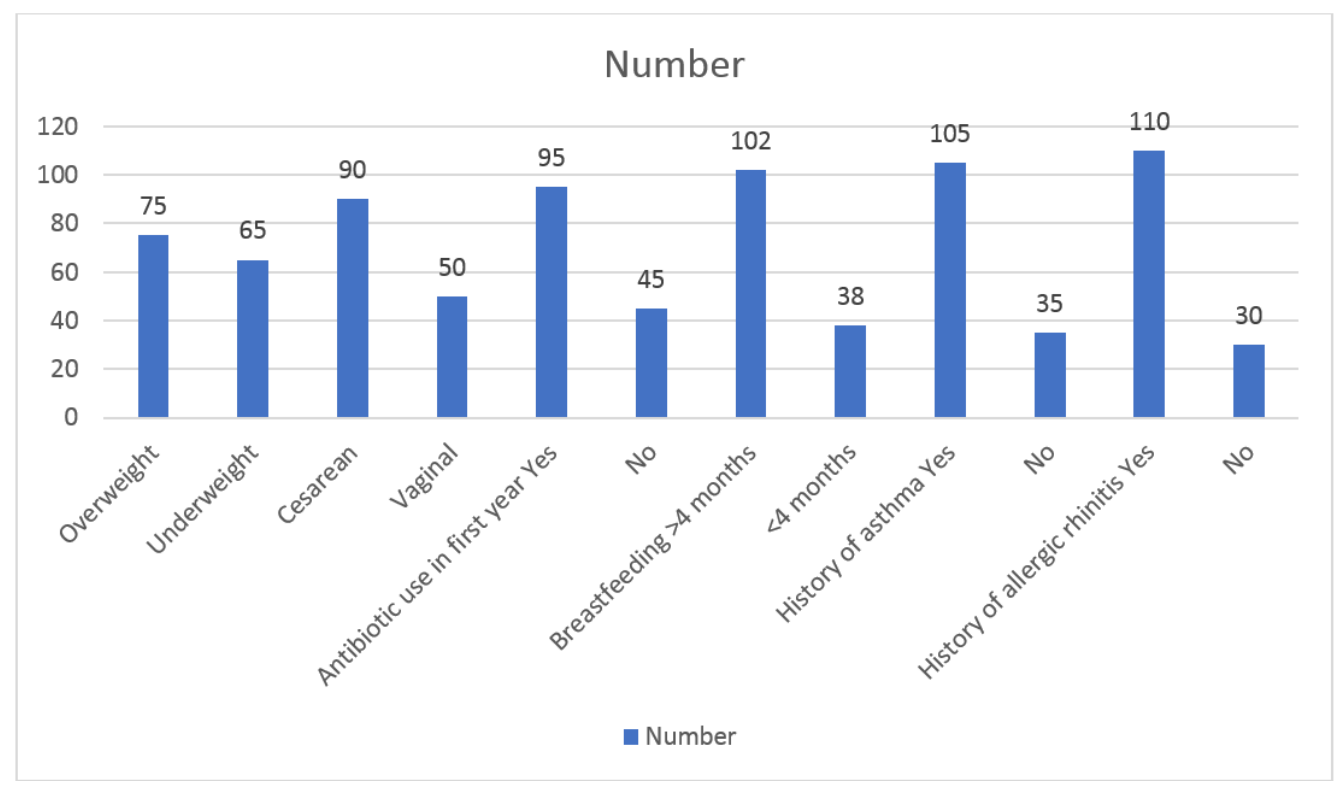

Graph I: Assessment of parameters

\section{Discussion}

Many epidemiological studies of AD have been performed worldwide, and it is generally accepted that $\mathrm{AD}$ is increasingly prevalent ${ }^{[7]}$. Around $50-75 \%$ of all children with early-onset atopic dermatitis are sensitized to one or more allergens, such as food allergens, house dust mites, or pets, whereas those with late-onset atopic dermatitis are less often sensitized ${ }^{[8]}$. However, intake of foods or exposure to airborne allergens is rarely the cause of exacerbations in atopic dermatitis; many patients with the disease are sensitized to foods without this playing a role in eczema activity ${ }^{[9]}$. Atopic dermatitis, particularly severe disease, in a child heralds other atopic diseases. A child with moderate to severe atopic dermatitis may have as much as $50 \%$ risk of developing asthma and $75 \%$ risk of developing hay fever ${ }^{[10]}$. The present study was conducted to assess cases of Atopic dermatitis.

In this study, out of 140 patients, males were 80 and females were 60. Mitchell et al. ${ }^{[11]}$ found Pearson's and Spearman's correlations identified relationships $(p<0.05)$ between self- efficacy with managing difficult child behaviour and child behaviour problems, parent depression and stress, parenting conflict and relationship satisfaction, and household income. There were also relationships between each of these variables and use of ineffective parenting strategies. Greater use of ineffective parenting strategies was associated with more severe atopic dermatitis. Using multiple linear regressions, child behaviour and household income explained unique variance in self-efficacy for managing difficult child behaviour; household income alone explained unique variance in use of ineffective parenting strategies. Self-efficacy for managing difficult child behaviour and self-efficacy for managing atopic dermatitis were positively correlated, and more successful self-reported performance of atopic dermatitis management tasks correlated with less permissive and less authoritarian parenting. Directly observed aversive child behaviour was associated with more severe atopic dermatitis, parent stress, and parent-reported child behaviour problems.

We observed that 75 children were overweight and 65 were 
underweight, 90 were born by ceasaran section and 50 by normal vaginal delivery, 95 had antibiotic use in first year of life and 45 had not, 102 had breastfeeding >4 months and 38 had not, 105 had history of asthma, 35 had not, 110 had history of allergic rhinitis and 30 had not. Choi et al. ${ }^{[12]}$ evaluated the prevalence, severity and risk factors for atopic dermatitis, a total of 6,453 preschool children from 59 kindergartens and 14 day-care centres were evaluated. Parents responded to an International Study of Asthma and Allergies in Childhood (ISAAC)-based questionnaire containing questions concerning 23 risk factors, as well as the prevalence, and severity of atopic dermatitis. Atopic dermatitis prevalence determined by dermatological examination was lower than the questionnaire-based prevalence (9.2\% vs $19.1 \%$ ). Most patients (96.2\%) had mild atopic dermatitis according to the EASI score (mean \pm SD 3.91 \pm 4.73 ; median 1.5; range 0.2-38.0). However, $17.4 \%$ had sleep disturbance, and $56.7 \%$ had not obtained complete remission of their rash over the previous 12 months. Among the 12 risk factors, "changing the patient's house to a newly built house during the first year of life" had significant odds ratio. In conclusion, the prevalence of atopic dermatitis in Korea in the ISAAC-based survey conducted by paediatricians was similar to that in several European countries, and lower than the 2006 Korean figure (28.9\%).

The shortcoming of the study is small sample size.

\section{Conclusion}

Authors found that increasing prevalence and severity of $\mathrm{AD}$ have considerable social and economic burdens on patients, families and societies.

\section{References}

1. Jee HM, Kim KW, Kim CS, Sohn MH, Shin DC, Kim KE. Prevalence of asthma, rhinitis and eczema in Korean children using the International Study of Asthma and Allergies in Childhood (ISSAC) Questionnaires. Pediatr Allergy Respir Dis (Korea) 2009;19:165-172.

2. Grize L, Gassner M, Wüthrich B, Bringolf-Isler B, TakkenSahli K, Sennhauser FH et al. Trends in prevalence of asthma, allergic rhinitis and atopic dermatitis in 5-7-year old Swiss children from 1992 to 2001. Allergy 2006;61:556-562.

3. Olesen AB, Bang K, Juul S, Thestrup-Pedersen K. Stable incidence of atopic dermatitis among children in Denmark during the 1990s. Acta Derm Venereol 2005;85:244-247.

4. Schultz Larsen F, Svensson A, Diepgen TL, From E. The occurrence of atopic dermatitis in Greenland. Acta Derm Venereol 2005;85:140-143.

5. Saeki H, Iizuka H, Mori Y, Akasaka T, Takagi H, Kitajima $\mathrm{Y}$ et al. Prevalence of atopic dermatitis in Japanese elementary schoolchildren. $\mathrm{Br} \mathrm{J}$ Dermatol 2005;152:110-114.

6. Saeki H, Oiso N, Honma M, Odajima H, Iizuka H, Kawada A et al. Comparison of prevalence of atopic dermatitis in Japanese elementary schoolchildren between 2001/2002 and 2007/2008. J Dermatol 2009;36:512-514.

7. Haileamlak A, Lewis SA, Britton J, Venn AJ, Woldemariam D, Hubbard R et al. Validation of the international study of asthma and allergies in children
(ISAAC) and U.K. criteria for atopic eczema in Ethiopian children. Br J Dermatol 2005;152:735-741.

8. Williams H, Robertson C, Stewart A, Aït-Khaled N, Anabwani G, Anderson $\mathrm{R}$ et al. Worldwide variations in the prevalence of symptoms of atopic eczema in the international study of asthma and allergies in childhood. J Allergy Clin Immunol 1999;103:125-138.

9. Hanifin JM, Thurston M, Omoto M, Cherill R, Tofte SJ, Graeber M. The eczema area and severity index (EASI): assessment of reliability in atopic dermatitis. EASI Evaluator Group. Exp Dermatol 2001;10:11-18.

10. Falade AG, Olawuyi JF, Osinusi K, Onadeko BO. Prevalence and severity of symptoms of asthma, allergic rhinoconjunctivitis, and atopic eczema in 6- to 7-year-old Nigerian primary school children: the International Study of Asthma and Allergies in Childhood. Med Princ Pract 2004;13:20-25

11. Mitchell AE, Fraser JA, Morawska A, Ramsbotham J, Yates P. Parenting and childhood atopic dermatitis: A cross-sectional study of relationships between parenting behaviour, skin care management, and disease severity in young children. International Journal of Nursing Studies. 2016;64:72-85.

12. Ho CL, Chang LI, Wu WF. The prevalence and risk factors of atopic dermatitis in 6-8 year-old first graders in taipei. Pediatrics \& Neonatology. 2019;60(2):166-71. 